\title{
REVIEW
}

\section{Use of Insulin Lispro Protamine Suspension in Pregnancy}

\author{
Annunziata Lapolla • Maria Grazia Dalfrà · Ester Romoli • \\ Matteo Bonomo · Paolo Moghetti
}

To view enhanced content go to www.advancesintherapy.com Received: July 3, 2015 / Published online: October 26, 2015

(c) The Author(s) 2015. This article is published with open access at Springerlink.com

\section{ABSTRACT}

Maternal metabolism changes substantially during pregnancy, which poses numerous challenges to physicians managing pregnancy in women with diabetes. Insulin is the agent of choice for glycemic control in pregnant women with diabetes, and the insulin analogs are particularly interesting for use in pregnancy. These agents may reduce the risk of hypoglycemia and promote a more physiological glycemic profile than regular human insulin in pregnant women with type 1 (T1D), type 2 (T2D), or gestational

Electronic supplementary material The online version of this article (doi:10.1007/s12325-015-0244-y) contains supplementary material, which is available to authorized users.

A. Lapolla $(\bowtie) \cdot$ M. Grazia Dalfrà

DPT Medicine, University of Padua, Padua, Italy

e-mail: annunziata.lapolla@unipd.it

\section{E. Romoli}

Medical Department, Eli Lilly Italia S.p.A.,

via Gramsci, 731, Sesto f.no, FI, Italy

M. Bonomo

DPT Medicine, Ospedale Niguarda, Milan, Italy

P. Moghetti

DPT Medicine, Verona University, Verona, Italy
(GDM) diabetes. However, there have been concerns regarding potential risk for crossing the placental barrier, mitogenic stimulation, teratogenicity, and embryotoxicity. Insulin lispro protamine suspension (ILPS), an intermediate- to long-acting insulin, has a stable and predictable pharmacological profile, and appears to have a favorable time-action profile and produce desirable basal and postprandial glycemic control. As the binding of insulin lispro is unaffected by the protamine molecule, ILPS is likely to have the same mitogenic and immunogenic potential as insulin lispro. Insulin lispro produces similar outcomes to regular insulin in pregnant women with T1D, T2D, or GDM, does not cross the placental barrier, and is considered a useful treatment option for pregnant women with diabetes. Clinical data support the usefulness of ILPS for basal insulin coverage in non-pregnant patients with T1D or T2D, and suggest that the optimal regimen, in terms of balance between efficacy and hypoglycemic risk, is a once-daily injection, especially in patients with T2D. Available data concerning use of ILPS in pregnant women are currently derived from retrospective analyses that 
involved, in total, $>1200$ pregnant women. These analyses suggest that ILPS is at least as safe and effective as neutral protamine Hagedorn insulin. Thus, available experimental and clinical data suggest that ILPS once daily is a safe and effective option for the management of diabetes in pregnant women.

Funding: Eli Lilly and Company.

Keywords: Fetal outcome; Gestational diabetes; Insulin lispro protamine suspension; Maternal outcome; Pregestational diabetes; Pregnancy

\section{INTRODUCTION}

The prevalence of diabetes is increasing globally $[1,2]$, as are the incidences of pre-existing and gestational diabetes (GDM) in pregnant women [3]. Since the prevalence of diabetes (both types 1 and 2) in children and adolescents is also increasing [4], it is likely that we will continue to see increases in the incidence of pregnancy complicated by diabetes.

Women with pre-existing type 1 diabetes (T1D) or type 2 diabetes (T2D) have increased risk of several maternal and fetal adverse outcomes during pregnancy [5-13]. In this context, increased glucose levels play an important role in the pathogenesis of congenital malformations and perinatal complications, and there is an association between poor glycemic control in the periconceptional period and increased risk of maternal and fetal anomalies [5, 9, 14-16].

It is therefore recommended that glycemic targets for pregnant women with diabetes be as close as possible to the normal range $[10,17$, 18], taking into account the physiological decreases in glucose and glycated hemoglobin
(HbA1c) levels that occur during pregnancy in non-diabetic women [19]. Very good glycemic control should thus be achieved, while avoiding hypoglycemic episodes [20] and ensuring that fetal growth is not compromised [21-23].

This review provides an overview of the insulins available for treating pregnant women with diabetes, with an emphasis on insulin analogs in general and on insulin lispro protamine suspension (ILPS), an intermediateto long-acting insulin, in particular. ILPS could be utilized for control of hyperglycemia during pregnancy. This article is based on previously conducted studies, and does not involve any new studies of human or animal subjects performed by any of the authors.

\section{PHYSIOLOGICAL CHANGES DURING NORMAL AND DIABETIC PREGNANCY}

Briefly, maternal metabolism changes substantially during pregnancy $[24,25]$. These changes occur to allow the efficient storage of nutrients during feeding and the rapid use of stored nutrients, with minimal catabolism of maternal protein, during fasting [26].

Early gestation is characterized by an increase in maternal fat stores and small increases in insulin sensitivity, to provide stored nutrients to meet the feto-placental and maternal demands of late gestation and lactation. Late pregnancy is characterized by markedly reduced insulin sensitivity and increased beta-cell responses, which lead to increases in maternal plasma glucose and free fatty acid levels, thereby allowing for greater availability of nutrients for fetal growth [25, 27].

When considering HbA1c monitoring, comparison of relevant data collected at Italian Diabetic Care Units from 445 non-diabetic pregnant women between weeks 
15 and 36 of pregnancy and from 384 non-diabetic non-pregnant women showed that HbA1c reference intervals were lower during pregnancy (4.0-5.5\% versus $4.8-6.2 \%$; median, $4.8 \%$ versus $5.6 \%, P<0.001$ ) [19]. HbA1c levels were also slightly higher during weeks 28-36 of pregnancy than during weeks 25-27 $(P<0.002)$ and weeks $15-24(P<0.001)$ [19]. However, HbA1c levels have shown poor correlation with mean, fasting, premeal, and postmeal blood glucose values, with the incidence of macrosomia and, in women with GDM, with pregnancy outcomes [28]. This suggests that the metabolic monitoring of pregnant women with diabetes should include not only HbA1c levels, but also daily glucose level monitoring, to capture glycemic peaks and glucose variability.

In addition to the changes characteristic of pregnant women without diabetes, women with GDM have an imbalance between tissue insulin requirements for glucose regulation and the ability of pancreatic beta cells to meet those requirements $[24,25]$. These patients also show hepatic insulin resistance and defects in insulin signaling [24, 25]. Impaired insulin sensitivity during early pregnancy is a predictor of GDM, whereas impaired beta-cell function is only evident when GDM has developed [29].

As pregnant women with T1D have a complete absence of endogenous insulin, the proper balance of accelerated starvation and facilitated anabolism, which is characteristic of pregnancy, must be achieved by therapeutic intervention [26]. This underlies the difficulty in maintaining glucose levels in the normal range and managing the resultant large daily blood glucose excursions that occur in pregnant women with T1D. These patients are also more susceptible to developing ketoacidosis if insulin is not appropriately administered, because lipolysis and ketogenesis progress without the compensatory effect of insulin for control [26]. Importantly, lipid and lipoprotein abnormalities are observed in pregnant women with T1D and poor glycemic control (but not in those with good glycemic control) and in their newborns with fetal macrosomia [30].

In pregnant women with $\mathrm{T} 2 \mathrm{D}$, pre-existing insulin resistance is exacerbated by pregnancy-related decreases in insulin sensitivity, so most patients who are diet-treated at the time of conception require insulin therapy early in pregnancy [26].

\section{INSULINS AVAILABLE FOR USE IN PREGNANCY}

Insulin is the treatment of choice for any type of diabetes during pregnancy $[10,31]$. In this context, the optimization of insulin therapy is critical to ensure (near-)normal glycemic control without the occurrence of hypoglycemia and with appropriate weight gain [31]. The physiological changes in glucose metabolism that occur in pregnant women increase demand for rapid-acting insulin postprandially and require that doses of intermediate- or long-acting insulins be adjusted throughout each trimester of pregnancy, to ensure constant and appropriate basal insulin levels [31].

Insulins available for use during pregnancy are shown in Table 1. The time-action profiles of the insulin analogs make these agents particularly interesting for use in pregnancy. These insulin preparations will therefore be the focus of this section.

In general, insulin analogs may reduce the risk of hypoglycemia and promote a more physiological glycemic profile than regular human insulin in pregnant women with T1D, T2D, or GDM [34]. However, there are a number of potential concerns associated with the use of 
Table 1 Insulins available for use in pregnancy in selected regions

\begin{tabular}{|c|c|}
\hline Insulin & Comments $[32,33]$ \\
\hline \multicolumn{2}{|l|}{ Human } \\
\hline Regular insulin & $\begin{array}{l}\text { No restrictions on use in diabetes during pregnancy; } \\
\text { does not cross the placental barrier }\end{array}$ \\
\hline $\mathrm{NPH}$ insulin (isophane insulin) & $\begin{array}{l}\text { No restrictions on use in diabetes during pregnancy; } \\
\text { does not cross the placental barrier }\end{array}$ \\
\hline \multicolumn{2}{|l|}{ Rapid-acting insulin analogs } \\
\hline Insulin aspart & $\begin{array}{l}\text { Can be used in pregnancy; data from two clinical trials (total of } 349 \text { exposed } \\
\text { pregnancies) do not indicate any adverse effect on pregnancy or feto-neonatal } \\
\text { health compared with human insulin }\end{array}$ \\
\hline Insulin glulisine & $\begin{array}{l}\text { Caution should be exercised when prescribing to pregnant women, and the drug } \\
\text { should only be used if the potential benefit justifies the potential risk to the fetus; } \\
\text { there are no well-controlled clinical studies, and data are limited in pregnant } \\
\text { women (fewer than } 300 \text { pregnancy outcomes) }\end{array}$ \\
\hline Insulin lispro & $\begin{array}{l}\text { Can be used in pregnancy; data from a large number of exposed pregnancies do not } \\
\text { indicate any adverse effect on pregnancy or feto-neonatal health }\end{array}$ \\
\hline \multicolumn{2}{|c|}{ Intermediate- and long-acting insulin analogs } \\
\hline Insulin detemir & $\begin{array}{l}\text { Can be considered during pregnancy, but any potential benefit must be weighed } \\
\text { against possible increased risk of adverse pregnancy outcomes; results of one clinical } \\
\text { trial suggest possible increased risk of serious adverse maternal outcomes compared } \\
\text { with isophane insulin; post-marketing data from an additional } 250 \text { outcomes from } \\
\text { pregnant women exposed to insulin detemir suggest no maternal or feto-neonatal } \\
\text { toxicity }\end{array}$ \\
\hline Insulin degludec & No clinical experience in pregnant women \\
\hline Insulin glargine & $\begin{array}{l}\text { May be considered during pregnancy, if necessary; no clinical data on exposed } \\
\text { pregnancies from controlled clinical studies available; data from pregnant women } \\
\text { (between } 300 \text { and } 1000 \text { pregnancy outcomes) indicate no adverse effects on } \\
\text { pregnancy, nor malformative or feto-neonatal toxicity }\end{array}$ \\
\hline ILPS & Limited clinical experience in pregnancy \\
\hline
\end{tabular}

ILPS insulin lispro protamine suspension, NPH neutral protamine Hagedorn

these agents during pregnancy. These concerns include: the risk of anti-insulin antibody development, which allows insulin to cross the placental barrier [35]; affinity for the insulin-like growth factor-1 (IGF-1) receptor and the consequent risk of mitogenic stimulation; and the potential risk of teratogenicity and embryotoxicity (see later text).

\section{Rapid-Acting Insulin Analogs}

The rapid-acting insulin analogs (RAIAs), insulin lispro and insulin aspart, reduce postprandial hyperglycemia more effectively than regular human insulin and both are approved for use in pregnancy by the European Medicines Agency [36, 37]. No 
clinical trials involving use of insulin glulisine in pregnant patients have been published [38] and, for this reason, its use in this population is not usually advised.

Although data from randomized controlled trials (RCTs) are limited, experience with insulin lispro and insulin aspart has generally indicated that these RAIAs produce similar outcomes to regular human insulin in pregnant women with T1D, T2D, or GDM [34, 39-42]. These latter findings have led to the conclusion that there is no evidence of an adverse effect of these insulins on pregnancy or on the health of the fetus/newborn [34, 36, 37, 41, 43, 44].

\section{Potential Immunogenicity}

The immunogenicity of RAIAs has not been well investigated. However, insulin lispro elicited similar levels of antibody formation to regular human insulin in 42 women with GDM [45] and the potential for antibody formation with insulin aspart and regular human insulin is similar in women with T1D or T2D [46]. Insulin lispro does not cross the placental barrier [45, 47]; no published data concerning the possible placental transfer of insulin aspart or insulin glulisine have been identified.

\section{Mitogenic Potential}

In vitro findings suggest that the mitogenic potential of insulin lispro and insulin aspart is similar to that of human insulin $[48,49]$, but that insulin glulisine may differ in this regard, inducing significantly greater proliferation than human insulin in IGF-1 receptor-expressing cells $(P<0.05)$ [49].

\section{Long-Acting Insulin Analogs}

The long-acting insulin analogs (LAIAs) have potential benefits in the management of pregnancy in women with T1D because of their ability to mitigate the risk of nocturnal hypoglycemia and to provide and maintain the stringent glycemic targets needed in this population. A number of studies have shown that insulin glargine and insulin detemir are safe and promote good glycemic control during pregnancy [34, 44, 50-52], and both can be considered for use in pregnant women (Table 1) $[53,54]$. There is currently no clinical experience with insulin degludec in pregnant women, although animal studies have not revealed any embryotoxicity or teratogenicity differences between insulin degludec and regular human insulin [55].

A meta-analysis of clinical studies comparing maternal and fetal outcomes in a total of 702 women with pregestational diabetes or GDM receiving either insulin glargine $(N=331)$ or neutral protamine Hagedorn (NPH) insulin (isophane insulin; $N=371$ ) found no significant differences in glycemic control or safety-related outcomes between the two insulins during pregnancy [56]. However, there was considerable heterogeneity among the eight studies included in the meta-analysis. No specific malformative or feto-neonatal toxicity has been observed with insulin glargine [53].

Similarly, post-marketing data indicate no adverse effects of insulin detemir on pregnancy, nor any malformative or feto-neonatal toxicity [54]. In an RCT involving 310 pregnant women with T1D, treatment with insulin detemir resulted in lower fasting plasma glucose levels than, and non-inferior HbA1c to, NPH insulin in late pregnancy. Rates of hypoglycemia were similar with the two insulins. However, there was a non-significantly higher frequency of serious maternal adverse events with insulin detemir compared with NPH insulin $(40 \%$ versus $31 \%$ ), although only $8-12 \%$ of these events were considered by the investigators to be possibly or probably related to 
investigational drugs [57]. Therefore, it was concluded that there were no concerns regarding the tolerability of either insulin. A subsequent analysis of this study comparing perinatal outcomes has shown that insulin detemir was as well tolerated as NPH insulin in terms of fetal and perinatal morbidity and mortality, and was without any specific safety concerns [58].

\section{Potential Immunogenicity}

We were unable to identify any data relating to the immunogenicity of LAIAs. However, an in vitro analysis using human placenta from uncomplicated pregnancies found that insulin glargine does not cross the placental barrier, except at concentrations higher than those that are likely to be seen clinically [59].

\section{Mitogenic Potential}

There are concerns regarding the affinity of LAIAs for the IGF-1 receptor and the consequent risk of mitogenic stimulation. However, the effects of insulin glargine and insulin detemir are not consistent across in vitro studies. In one study, both LAIAs had a lower affinity for the insulin receptor and a higher affinity for the IGF-1 receptor than human insulin [49]. In another study, the affinities of insulin glargine and insulin detemir for these receptors were concentration-dependent [48]. Overall, compared with human insulin, insulin glargine had similar or greater affinity for both the insulin and IGF-1 receptors [48, 60], whereas insulin detemir had similar or lower affinity for both receptors [48].

Insulin glargine has two main active metabolites, M1 and M2 [60]. The M1 metabolite is the main compound detected in plasma after administration and is responsible for the metabolic activity of insulin glargine in patients with T1D [61] and T2D [62]. In an in vitro study, the binding affinity of M1 and M2 to insulin receptors was similar to that of the parent compound, but they had lower affinity than insulin glargine for IGF-1 receptors in cells expressing these receptors [60]. The affinity of these metabolites for IGF-1 receptors was similar to that of human insulin in cells expressing these receptors, and their mitogenicity was similar to that of human insulin in human osteosarcoma Saos-2 cells [60].

Although these in vitro findings suggest an increased mitogenic potential of LAIAs as compared with human insulin and RAIAs [49], data are not conclusive, particularly with respect to insulin glargine, as its main active metabolite, M1, has low affinity for IGF-1 receptors [60]. Additionally, available clinical data do not show differences in the rate of mitogenic changes between patients with diabetes treated with insulin glargine and those receiving regular human insulin [44] and results of the ORIGIN trial (ClinicalTrials.gov identifier, NCT00069784) do not support mitogenic potential with insulin glargine [63]. In this latter trial, after a mean of 6.2 years of follow-up, patients treated with insulin glargine had a similar risk of cancer and cancer-related outcomes as patients who received standard care (not defined) [63].

\section{ILPS}

\section{Pharmacology}

To regulate glucose metabolism appropriately in diabetic patients, low, steady basal insulin levels should ideally be maintained during fasting periods. LAIAs were developed to achieve this result, by using simple titration schedules, while avoiding the wide pharmacological variability 
of traditional long-acting non-analog insulin preparations.

ILPS, an intermediate- to long-acting insulin, is a stable formulation of co-crystalized insulin lispro and protamine [64] that appears to have a favorable time-action profile and to produce desirable basal and postprandial glycemic control in patients with T1D and T2D [65]. ILPS has shown pharmacokinetic and pharmacodynamic properties similar to those of NPH insulin in healthy volunteers [66]. However, in patients with T1D, time to peak insulin concentration tended to be shorter (not significant) with ILPS than NPH insulin [67].

The duration of glucose-lowering activity of a single dose of ILPS $0.8 \mathrm{U} / \mathrm{kg}$ ( $>23 \mathrm{~h}$ ) supports its use once daily and did not differ significantly from that observed with insulin glargine or insulin detemir in patients with T2D [68]. However, ILPS had significantly greater glucose-lowering activity and produced an earlier maximum pharmacodynamic response (measured by glucose infusion rate during euglycemic glucose clamp testing) compared with both insulins [68]. Similarly, in patients with T1D, ILPS produced an earlier and larger maximum pharmacodynamic response than insulin detemir (also measured by glucose infusion rate during euglycemic glucose clamp testing), with a similar duration of action of just under $24 \mathrm{~h}$ ( 22 versus $23 \mathrm{~h}$, respectively) for both agents [69].

Interestingly, compared with insulin glargine given at a single equivalent dose, ILPS was associated with lower pharmacodynamic intrasubject variability, more rapid onset of action, and greater glucose-lowering activity in patients with T1D [70]. These characteristics may provide a more predictable response in these patients [70]. The pharmacological effect of ILPS in patients with T2D was dose-dependent across the dose range of $0.4-1.2 \mathrm{U} / \mathrm{kg}$ [68]. Due to an increase in the risk of hypoglycemia with twice-daily dosing, a once-daily schedule appears to provide the best balance between efficacy and hypoglycemic risk [65].

The receptor binding of insulin lispro is unaffected by the protamine molecule and ILPS therefore has the same binding profile as insulin lispro. On this basis, the mitogenic and immunogenic potentials of ILPS are expected to be the same as those of insulin lispro.

\section{Clinical Trials}

Since data from pregnant women with diabetes are limited, this section provides an overview of clinical studies conducted in non-pregnant women with pregestational diabetes or GDM.

In a prospective observational study in 64 patients with T1D or T2D whose diabetes was inadequately controlled with oral antidiabetes medications or other insulin regimens, ILPS improved glycemic control without significantly increasing hypoglycemic episodes when used as basal insulin in intensive insulin therapy [71]. Importantly, ILPS, as part of a self-prepared combination with insulin lispro, was not associated with a significant change in binding levels to antibodies cross-reactive to different insulin species $(-0.1 \%$ with ILPS plus insulin lispro versus $-0.3 \%$ with regular human insulin plus NPH insulin; no significant difference between treatments) in a randomized, open-label trial conducted in patients with T1D or T2D [72].

ILPS once or twice daily has been compared with other LAIAs in non-pregnant women with diabetes in randomized trials of 24 to 36 weeks duration (Table 2). Overall, ILPS achieved similar glycemic control to insulin detemir and insulin glargine, without increasing the 


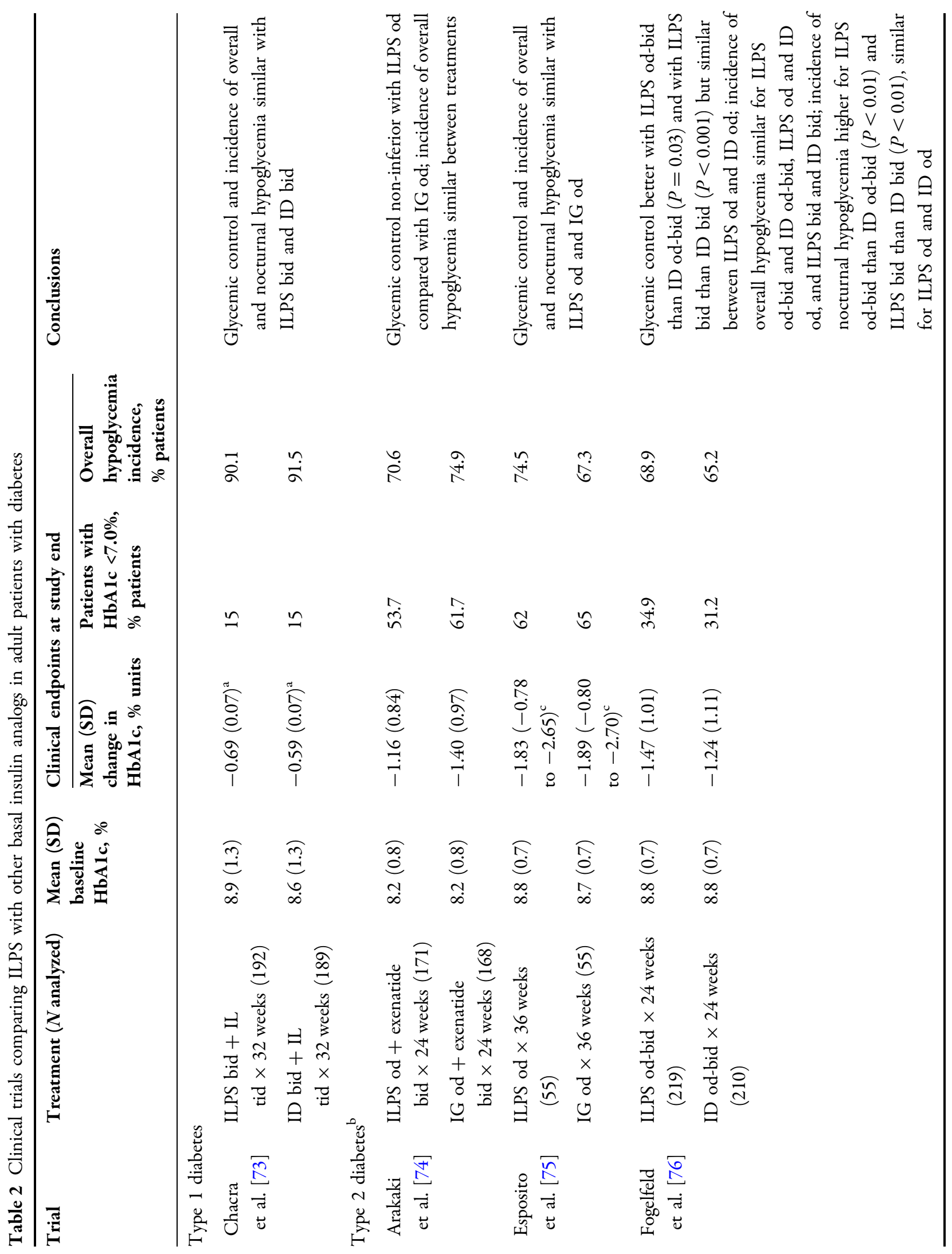




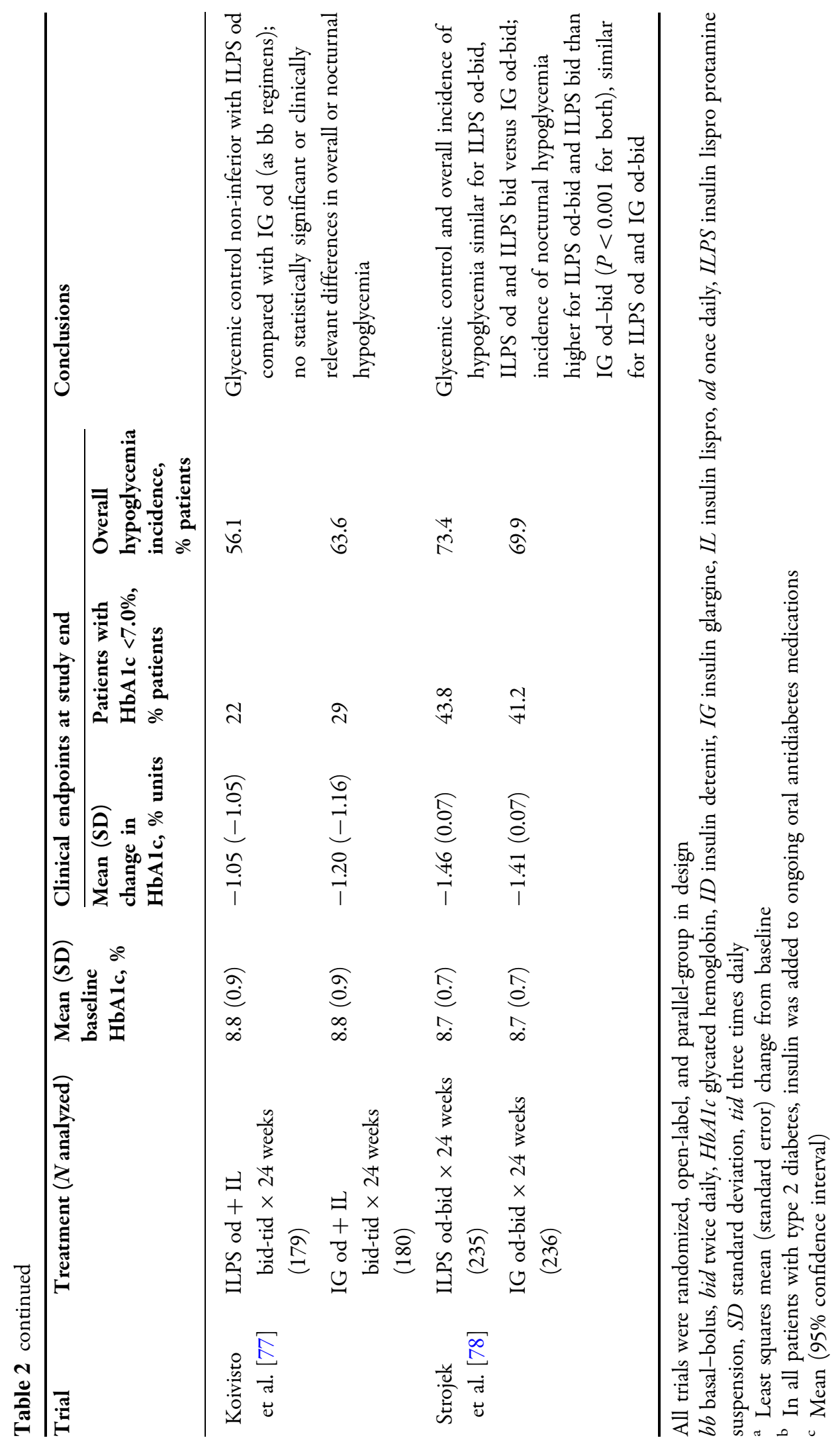


risk of hypoglycemic episodes (overall or nocturnal) or weight gain when used as once-daily basal supplementation in patients with T2D receiving oral antidiabetes medications (Table 2) [74-78]. In one of these studies, ILPS was administered with prandial insulin lispro as part of a basal-bolus regimen and compared with a basal-bolus regimen of insulin glargine plus insulin lispro [77]. Glycemic control (change in HbA1c) and the risk of hypoglycemia were similar with both regimens.

Notably, the glycemic control achieved with ILPS was often maintained with lower total daily insulin doses than those required with insulin detemir or insulin glargine in patients with T1D [73] or T2D [74, 75]. In some studies, when administered twice daily, ILPS appeared to be associated with increased risk of nocturnal hypoglycemia (Table 2 ) [73, 76, 78].

These data were confirmed in a meta-analysis [79] and support the usefulness of ILPS as an insulin analog for basal coverage in non-pregnant patients with T1D or T2D. Furthermore, the findings suggest that the optimal regimen, in terms of balance between efficacy and hypoglycemic risk, is a once-daily injection [79], especially in patients with T2D [65].

\section{ILPS in Pregnancy}

Insulin lispro does not cross the placental barrier and is considered a useful treatment option for pregnant women with diabetes [34]. As discussed in the Pharmacology section, ILPS has the same binding properties as insulin lispro, and also has a stable and predictable pharmacological profile. Available data concerning use of ILPS in pregnant women are currently derived from retrospective analyses conducted in Italian centers.
A retrospective cohort study of 89 pregnant women with T2D or GDM showed that basal therapy with either ILPS $(N=53)$ or NPH insulin $(N=36)$, in addition to RAIAs (insulin aspart or insulin lispro) in most patients, resulted in similar maternal and pregnancy outcomes, including glycemic control, hypertension rates, and number of hypoglycemic events. However, NPH insulin resulted in a greater prevalence of high-ponderal-index infants (three versus zero infants with index $>2.85 \mathrm{~g} / \mathrm{cm}^{3}$; all three were also receiving a RAIA) and in higher total insulin doses than ILPS. Both insulins appeared safe in this population [80].

A larger retrospective study evaluated data from 612 pregnant women with T1D, T2D, or GDM treated with ILPS insulin and data from a control group of 793 similar women treated with NPH insulin [81]. HbA1c improved during pregnancy in both prepregnancy diabetes groups (Table 3). Although no statistical results were presented, there were fewer severe hypoglycemic events and ketoacidosis events reported in ILPS-treated women with T1D than $\mathrm{NPH}$ insulin-treated women with T1D. In women with T1D or T2D, the frequency of cesarean section was lower with ILPS than with $\mathrm{NPH}$ insulin (Table 3) [81]. In patients with GDM, maternal and fetal outcomes were not different in the two treatment groups (mean maternal HbA1c values were not reported). Thus, these data also suggest that ILPS is safe and effective for use in pregnancy.

A separate and more recent Italian multicenter observational retrospective study evaluated pregnancy outcomes in another 119 women with T1D and 814 women with GDM treated during pregnancy with ILPS or NPH insulin [82]. Among patients with T1D, HbA1c did not differ significantly between the two treatment groups either before the pregnancy or 


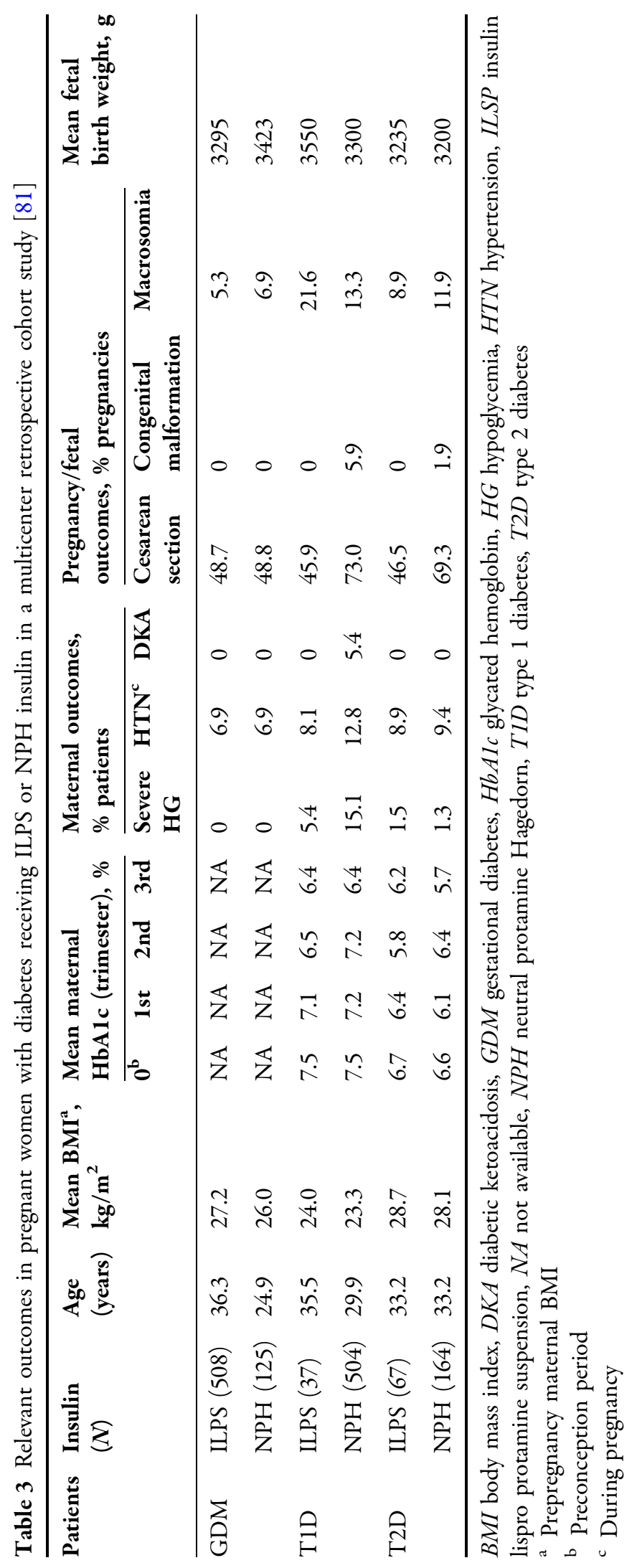


Table 4 Pregnancy outcome and fetal parameters relating to women with T1D and GDM treated with ILPS or NPH insulin in a multicenter observational retrospective study (reproduced with permission from [82])

\begin{tabular}{|c|c|c|c|c|c|c|}
\hline \multirow[t]{2}{*}{ Outcome } & \multicolumn{3}{|l|}{ T1D } & \multicolumn{3}{|l|}{ GDM } \\
\hline & $\begin{array}{l}\text { ILPS } \\
(N=58)\end{array}$ & $\begin{array}{l}\text { NPH } \\
(N=61)\end{array}$ & $P$ value & $\begin{array}{l}\text { ILPS } \\
(N=572)\end{array}$ & $\begin{array}{l}\text { NPH } \\
(N=242)\end{array}$ & $P$ value \\
\hline Weight gain during pregnancy, $\mathrm{kg}$ & $11.9(4.6)$ & $13.2(9.4)$ & $\mathrm{ns}$ & $10.2(6.1)$ & $9.7(4.6)$ & ns \\
\hline $\begin{array}{l}\text { HbAlc preconception } \mathrm{a} / \mathrm{at} \\
\text { diagnosis, }{ }^{\mathrm{b}} \mathrm{mmol} / \mathrm{mol}\end{array}$ & $61.7(11.9)$ & $57.4(13)$ & ns & $36.6(4.2)$ & $35.5(3.1)$ & 0.04 \\
\hline $\mathrm{HbAlc}$ first trimester, $\mathrm{mmol} / \mathrm{mol}$ & $56.3(11.9)$ & $56.3(11.9)$ & ns & - & - & - \\
\hline $\mathrm{HbAlc}$ second trimester, $\mathrm{mmol} / \mathrm{mol}$ & $48.6(7.5)$ & $47.5(7.5)$ & ns & - & - & - \\
\hline $\mathrm{HbAlc}$ third trimester, $\mathrm{mmol} / \mathrm{mol}$ & $49.7(6.4)$ & $47.5(8.6)$ & $\mathrm{ns}$ & $36.3(6.4)$ & $35.6(4.2)$ & $\mathrm{ns}$ \\
\hline Fasting glucose third trimester, $\mathrm{mmol} / \mathrm{l}$ & $6.0(1.4)$ & $7.7(2.2)$ & 0.001 & $4.9(0.7)$ & $6.3(1.5)$ & $<0.001$ \\
\hline Severe hypoglycemic episodes, \% & 5.2 & 13.1 & ns & 0.3 & 2.1 & ns \\
\hline Ketoacidosis episodes, \% & 0 & 0 & - & 0 & 0.4 & ns \\
\hline $\begin{array}{l}\text { Basal insulin need at term } \\
\text { of pregnancy, } \mathrm{U} / \mathrm{kg}\end{array}$ & $0.40(0.20)$ & $0.33(0.14)$ & ns & $0.12(0.09)$ & $0.11(0.07)$ & ns \\
\hline Delivery, gestational week & $37.4(2.4)$ & $36.9(2.2)$ & $\mathrm{ns}$ & $38.4(1.9)$ & $37.8(1.7)$ & 0.001 \\
\hline Cesarean section, $\%$ & 48.2 & 63.9 & 0.001 & 31.2 & 46.2 & 0.01 \\
\hline $\begin{array}{l}\text { Preterm delivery } \\
\qquad(<37 \text { gestational weeks), \% }\end{array}$ & 15.5 & 32.8 & 0.05 & 8.6 & 14.9 & 0.01 \\
\hline Stillbirths, \% & 3.4 & 1.6 & ns & 0.5 & 0.4 & $\mathrm{~ns}$ \\
\hline Birth weight, g & $3372(788)$ & $3304(745)$ & ns & $3304(505)$ & $3286(567)$ & ns \\
\hline Ponderal index, $\mathrm{g} / \mathrm{cm}^{3}$ & $2.75(0.4)$ & $2.87(0.5)$ & $\mathrm{ns}$ & $2.72(0.3)$ & $2.78(0.6)$ & $\mathrm{ns}$ \\
\hline Ponderal index $\geq 2.85 \mathrm{~g} / \mathrm{cm}^{3}, \%$ & 29.3 & 42.6 & $\mathrm{~ns}$ & 18.2 & 26.4 & 0.01 \\
\hline Macrosomia (>4000 g), \% & 18.9 & 16.3 & ns & 6.1 & 5.3 & 0.01 \\
\hline Small for gestational age, \% & 5.2 & 0 & ns & 3.1 & 5.4 & ns \\
\hline Large for gestational age, $\%$ & 43.1 & 37.7 & ns & 16.6 & 19.4 & ns \\
\hline Congenital malformations, $\%$ & 6.9 & 6.5 & ns & 0.5 & 1.6 & ns \\
\hline Neonatal hypoglycemia, \% & 8.6 & 4.9 & ns & 2.3 & 4.1 & 0.01 \\
\hline
\end{tabular}

Data are presented as mean (standard deviation), unless stated otherwise

GDM gestational diabetes, $H b A I c$ glycated hemoglobin, ILPS insulin lispro protamine suspension, NPH neutral protamine Hagedorn, $n s$ not significant, TID type 1 diabetes

${ }^{a}$ In patients with T1D

b In patients with GDM

during each trimester; however, third trimester mean fasting blood glucose levels were significantly lower in ILPS-treated women
(Table 4). Rates of severe hypoglycemic episodes during pregnancy and insulin requirements at the end of pregnancy were 
similar between treatment groups and no patient had a ketoacidosis episode. As regards pregnancy outcomes, rates of cesarean section and preterm delivery were significantly lower in women treated with ILPS than in those treated with NPH insulin, although the mean duration of pregnancy did not differ between treatment groups. Fetal outcomes, including rates of congenital malformation, were also similar in the ILPS and NPH groups, with the exception that a slightly higher proportion of newborns in the NPH group had a ponderal index $\geq 2.85 \mathrm{~g}$ / $\mathrm{cm}^{3}$ (not significant; Table 4).

Among women with GDM, third trimester HbA1c did not differ significantly between treatment groups, but fasting blood glucose was lower in ILPS-treated women (Table 4). There were no significant between-treatment differences in the rates of severe hypoglycemic or ketoacidotic episodes, or in insulin requirements at the end of the pregnancy. Pregnancy outcomes were generally better in ILPS- than NPH-treated women, with the duration of the pregnancy being significantly longer, and the cesarean section and preterm delivery rates lower in the ILPS-treated group. When fetal outcomes were considered, ILPS was associated with a significantly higher incidence of macrosomia, and significantly fewer episodes of neonatal hypoglycemia and newborns with ponderal index $\geq 2.85 \mathrm{~g} / \mathrm{cm}^{3}$ (Table 4 ). This higher rate of macrosomia in the ILPS group was possibly a result of the longer duration of pregnancy, because the incidence of neonates with a high ponderal index was lower in this group than the NPH group, ruling out dysmorphic growth as an etiological factor.

Bivariate logistic regression analysis of birth weight and neonatal complications, including congenital malformations and events associated with perinatal complications, revealed no statistically significant differences between
ILPS and NPH treatment. This large study therefore confirms that use of ILPS in conjunction with rapid-acting analogs in pregnant patients with T1D or GDM is safe in terms of maternal and fetal outcomes, and this regimen achieves good metabolic control while limiting fetal overgrowth [82].

\section{CONCLUSION}

Maternal metabolism changes during pregnancy, posing numerous challenges in the management of women with diabetes. As insulin is the agent of choice for glycemic control in these patients, selecting the most appropriate insulin formulation is important. Although a number of insulins are available for use during pregnancy, insulin analogs are particularly interesting for this use, as they appear to reduce the risk of hypoglycemia and promote a more physiological glycemic profile than regular human insulin in pregnant women with T1D, T2D, or GDM. The RAIAs, insulin lispro and insulin aspart, and LAIAs, insulin glargine and insulin detemir, can all be used in pregnancy and are considered safe in terms of maternal and fetal health. ILPS, an intermediate- to long-acting insulin, is a stable formulation of co-crystalized insulin lispro and protamine that is expected to have the same mitogenic and immunogenic potentials as insulin lispro. Clinical data support the usefulness of ILPS as a basal insulin in non-pregnant patients with T1D or T2D, and suggest the optimal regimen, in terms of balance between efficacy and hypoglycemic risk, is a once-daily injection, especially in patients with T2D.

Most information regarding the use of insulins in pregnant women with diabetes is based on the results of observational studies; the sample sizes of all RCTs comparing different 
insulin formulations in pregnant women have not been adequate to allow sufficient power to detect differences in neonatal outcomes. Data concerning use of ILPS during pregnancy are no exception to this, although findings from more than 1200 pregnant women with T1D, T2D, or GDM receiving this insulin are available and have been compared with outcomes in pregnant women receiving NPH insulin [81, 82]. Results of these retrospective studies suggest that ILPS is at least as safe and effective as NPH insulin in pregnant women.

Therefore, until adequate RCTs are performed to provide more definitive findings, available experimental and clinical information indicates that ILPS has a stable and predictable pharmacological profile and appears to be a safe and effective option for pregnant women with diabetes.

\section{ACKNOWLEDGMENTS}

The article processing charges for this publication were funded by Eli Lilly and Company. The authors thank Caroline Spencer and Dr. Janet Douglas (Rx Communications, Mold, UK) for providing editorial assistance in the preparation of this article. Support for this assistance was funded by Eli Lilly and Company. All named authors meet the International Committee of Medical Journal Editors (ICMJE) criteria for authorship for this manuscript, take responsibility for the integrity of the work as a whole, and have given final approval to the version to be published.

Disclosures. Ester Romoli is a full-time employee of Eli Lilly Italia S.p.A. Maria Grazia Dalfrà, Matteo Bonomo, Paolo Moghetti, and Annunziata Lapolla have declared no conflicts of interest in relation to this work.
Compliance with ethics guidelines. This article is based on previously conducted studies, and does not involve any new studies of human or animal subjects performed by any of the authors.

Open Access. This article is distributed under the terms of the Creative Commons Attribution-NonCommercial 4.0 International License (http://creativecommons.org/licenses/ by-nc/4.0/), which permits any noncommercial use, distribution, and reproduction in any medium, provided you give appropriate credit to the original author(s) and the source, provide a link to the Creative Commons license, and indicate if changes were made.

\section{REFERENCES}

1. International Diabetes Foundation. IDF Diabetes Atlas. 6th ed. Brussels, Belgium: International Diabetes Federation; 2013. http://www.idf.org/ diabetesatlas. Accessed 14 Aug 2014.

2. Chen L, Magliano DJ, Zimmet PZ. The worldwide epidemiology of type 2 diabetes mellitus-present and future perspectives. Nat Rev Endocrinol. 2012;8:228-36.

3. Lawrence JM, Contreras R, Chen W, Sacks DA. Trends in the prevalence of preexisting diabetes and gestational diabetes mellitus among a racially/ ethnically diverse population of pregnant women, 1999-2005. Diabetes Care. 2008;31:899-904.

4. Dabelea D, Mayer-Davis EJ, Saydah S, SEARCH for Diabetes in Youth Study, et al. Prevalence of type 1 and type 2 diabetes among children and adolescents from 2001 to 2009. JAMA. 2014;311:1778-86.

5. Gizzo S, Patrelli TS, Rossanese $M$, Noventa $M$, Berretta R, Di Gangi S, Bertin M, Gangemi M, Nardelli GB. An update on diabetic women obstetrical outcomes linked to preconception and pregnancy glycemic profile: a systematic literature review. Sci World J. 2013;2013:1-9. doi:10.1155/ $2013 / 254901$.

6. Negrato CA, Mattar R, Gomes MB. Adverse pregnancy outcomes in women with diabetes. Diabetol Metab Syndr. 2012;4:41. 
7. Corrigan N, Brazil DP, McAuliffe F. Fetal cardiac effects of maternal hyperglycemia during pregnancy. Birth Defects Res A Clin Mol Teratol. 2009;85:523-30.

8. Riskin-Mashiah S, Younes G, Damti A, Auslender R. First-trimester fasting hyperglycemia and adverse pregnancy outcomes. Diabetes Care. 2009;32: $1639-43$.

9. Inkster ME, Fahey TP, Donnan PT, Leese GP, Mires GJ, Murphy DJ. Poor glycated haemoglobin control and adverse pregnancy outcomes in type 1 and type 2 diabetes mellitus: systematic review of observational studies. BMC Pregnancy Childbirth. 2006;6:30.

10. ACOG Committee on Practice Bulletins. ACOG Practice Bulletin. Clinical management guidelines for obstetrician-gynecologists. Number 60, March 2005. Pregestational diabetes mellitus. Obstet Gynecol. 2005;2005(105):675-85.

11. Lapolla A, Dalfrà MG, Fedele D. Insulin therapy in pregnancy complicated by diabetes: are insulin analogs a new tool? Diabetes Metab Res Rev. 2005;21:241-52.

12. Lapolla A, Dalfrà MG, Di Cianni G, Bonomo $M$, Parretti E, Mello G, Scientific Committee of the GISOGD Group. A multicenter Italian study on pregnancy outcome in women with diabetes. Nutr Metab Cardiovasc Dis. 2008;18:291-7.

13. Lapolla A, Dalfrà MG, Fedele D. Pregnancy complicated by type 2 diabetes: an emerging problem. Diabetes Res Clin Pract. 2008;80:2-7.

14. Jensen DM, Damm $P$, Ovesen $P$, et al. Microalbuminuria, preeclampsia, and preterm delivery in pregnant women with type 1 diabetes: results from a nationwide Danish study. Diabetes Care. 2010;33:90-4.

15. Kerssen A, de Valk HW, Visser GH. Forty-eight-hour first-trimester glucose profiles in women with type 1 diabetes mellitus: a report of three cases of congenital malformation. Prenat Diagn. 2006;26:123-7.

16. Lapolla A, Dalfrà MG, Fedele D. Pregnancy complicated by diabetes: what is the best level of HbA1c for conception? Acta Diabetol. 2010;47: 187-92.

17. Kitzmiller JL, Block JM, Brown FM, et al. Managing preexisting diabetes for pregnancy: summary of evidence and consensus recommendations for care. Diabetes Care. 2008;31:1060-79.

18. Inzucchi SE, Bergenstal RM, Buse JB, et al. Management of hyperglycaemia in type 2 diabetes: a patient-centered approach. Position statement of the American Diabetes Association
(ADA) and the European Association for the Study of Diabetes (EASD). Diabetologia. 2012;55:1577-96.

19. Mosca A, Paleari R, Dalfrà MG, et al. Reference intervals for hemoglobin A1c in pregnant women: data from an Italian multicenter study. Clin Chem. 2006;52:1138-43.

20. Evers IM, ter Braak EW, de Valk HW, van Der Schoot B, Janssen N, Visser GH. Risk indicators predictive for severe hypoglycemia during the first trimester of type 1 diabetic pregnancy. Diabetes Care. 2002;25:554-9.

21. Kanda E, Matsuda Y, Makino Y, Matsui H. Risk factors associated with altered fetal growth in patients with pregestational diabetes mellitus. J Matern Fetal Neonatal Med. 2012;25:1390-4.

22. Rosenn BM, Miodovnik M. Glycemic control in the diabetic pregnancy: is tighter always better? J Matern Fetal Med. 2000;9:29-34.

23. Combs CA, Gunderson E, Kitzmiller JL, Gavin LA, Main EK. Relationship of fetal macrosomia to maternal postprandial glucose control during pregnancy. Diabetes Care. 1992;15:1251-7.

24. Lain KY, Catalano PM. Metabolic changes in pregnancy. Clin Obstet Gynecol. 2007;50:938-48.

25. Di Cianni G, Miccoli R, Volpe L, Lencioni C, Del Prato S. Intermediate metabolism in normal pregnancy and in gestational diabetes. Diabetes Metab Res Rev. 2003;19:259-70.

26. Buchanan TA. Metabolic changes during normal and diabetic pregnancy. In: Reece EA, Coustan DR, editors. Diabetes mellitus in pregnancy. New York: Churchill Livingstone; 1995. p. 59-77.

27. Ryan EA. Hormones and insulin resistance during pregnancy. Lancet. 2003;362:1777-8.

28. Hod M, Yogev Y. Goals of metabolic management of gestational diabetes: is it all about the sugar? Diabetes Care. 2007;30(Suppl 2):S180-7.

29. Lapolla A, Dalfrà MG, Mello G, et al. Early detection of insulin sensitivity and beta-cell function with simple tests indicates future derangements in late pregnancy. J Clin Endocrinol Metab. 2008;93: 876-80.

30. Merzouk H, Bouchenak M, Loukidi B, Madani S, Prost J, Belleville J. Fetal macrosomia related to maternal poorly controlled type 1 diabetes strongly impairs serum lipoprotein concentrations and composition. J Clin Pathol. 2000;53:917-23.

31. Negrato CA, Montenegro RM Jr, Mattar R, et al. Dysglycemias in pregnancy: from diagnosis to 
treatment. Brazilian consensus statement. Diabetol Metab Syndr. 2010;2(27):5-14.

32. European Medicines Agency. European Medicines Agency. http://www.ema.europa.eu/ema/. Accessed 12 May 2015.

33. FDA. US Food and Drug Administration. http:// www.accessdata.fda.gov/scripts/cder/drugsatfda/ index.cfm. Accessed 12 May 2015.

34. Negrato CA, Montenegro Junior RM, Von Kostrisch LM, Guedes MF, Mattar R, Gomes MB. Insulin analogues in the treatment of diabetes in pregnancy. Arq Bras Endocrinol Metabol. 2012;56:405-14.

35. Menon RK, Cohen RM, Sperling MA, Cutfield WS, Mimouni F, Khoury JC. Transplacental passage of insulin in pregnant women with insulin-dependent diabetes mellitus. Its role in fetal macrosomia. N Engl J Med. 1990;323:309-15.

36. Insulin Aspart: Summary of product characteristics (EU) (2013). http://www.medicines.org.uk/emc/ medicine/8591/SPC/NovoMix +30+Penfill $+100+$ $\mathrm{U}+\mathrm{ml} \% 2 \mathrm{c}+$ NovoMix $+30+$ FlexPen $+100+\mathrm{U}+\mathrm{ml} /$. Accessed 9 May 2014.

37. Insulin Lispro: Summary of Product Characteristics (EU) (2014). http://www.medicines.org.uk/emc/ medicine/9314/SPC/Humalog $+100 \mathrm{U}+\mathrm{ml} \% 2 \mathrm{c}+$ solution + for + injection + in + vial $\% 2 c++$ Humalog + $100 \mathrm{U}+\mathrm{ml} \% 2 \mathrm{c}++$ solution + for + injection $+\mathrm{in}+$ Cartridge $\% 2 c++$ Humalog + KwikPen $+100 U+\mathrm{ml} \%$ 2c+solution+for+injection/. Accessed 9 May 2014.

38. Insulin Glulisine: Summary of product characteristics (EU) (2013). http://www.medicines. org.uk/emc/medicine/26476/SPC/Apidra+100+Units + ml\%2c+solution+for+injection+in+a+cartridge/. Accessed 12 May 2015.

39. García-Domínguez M, Herranz L, Hillman N, et al. Use of insulin lispro during pregnancy in women with pregestational diabetes mellitus. Med Clin (Barc). 2011;137:581-6.

40. Gonzalez Blanco C, Ballesteros AC, Saladich IG, Pla RC. Glycemic control and pregnancy outcomes in women with type 1 diabetes mellitus using lispro versus regular insulin: a systematic review and meta-analysis. Diabetes Technol Ther. 2011;13:907-11.

41. Edson EJ, Bracco OL, Vambergue A, Koivisto V. Managing diabetes during pregnancy with insulin lispro: a safe alternative to human insulin. Endocr Pract. 2010;16:1020-7.

42. Lapolla A, Dalfrà MG, Spezia R, et al. Outcome of pregnancy in type 1 diabetic patients treated with insulin lispro or regular insulin: an Italian experience. Acta Diabetol. 2008;45:61-6.

43. Durnwald CP, Landon MB. Insulin analogues in the management of the pregnancy complicated by diabetes mellitus. Curr Diab Rep. 2011;11:28-34.

44. Torlone E, Di Cianni G, Mannino D, Lapolla A. Insulin analogs and pregnancy: an update. Acta Diabetol. 2009;46:163-72.

45. Jovanovic L, Ilic S, Pettitt DJ, et al. Metabolic and immunologic effects of insulin lispro in gestational diabetes. Diabetes Care. 1999;22:1422-7.

46. Lindholm A, Jensen LB, Home PD, Raskin P, Boehm $\mathrm{BO}$, Råstam J. Immune responses to insulin aspart and biphasic insulin aspart in people with type 1 and type 2 diabetes. Diabetes Care. 2002;25:876-82.

47. Boskovic R, Feig DS, Derewlany L, Knie B, Portnoi G, Koren G. Transfer of insulin lispro across the human placenta: in vitro perfusion studies. Diabetes Care. 2003;26:1390-4.

48. Varewijck AJ, Goudzwaard JA, Brugts MP, Lamberts SW, Hofland LJ, Janssen JA. Insulin glargine is more potent in activating the human IGF-I receptor than human insulin and insulin detemir. Growth Horm IGF Res. 2010;20:427-31.

49. Sciacca L, Cassarino MF, Genua $\mathrm{M}$, et al. Insulin analogues differently activate insulin receptor isoforms and post-receptor signalling. Diabetologia. 2010;53:1743-53.

50. Pollex E, Moretti ME, Koren G, Feig DS. Safety of insulin glargine use in pregnancy: a systematic review and meta-analysis. Ann Pharmacother. 2011;45:9-16.

51. Lapolla A, Di Cianni G, Bruttomesso D, et al. Use of insulin detemir in pregnancy: a report on 10 Type 1 diabetic women. Diabet Med. 2009;26:1181-2.

52. Di Cianni G, Torlone E, Lencioni C, Italian Diabetes and Pregnancy Study Group, et al. Italian Society of Diabetology. Perinatal outcomes associated with the use of glargine during pregnancy. Diabet Med. 2008;25:993-6.

53. Insulin Glargine: Summary of product characteristics (EU) (2014). http://www.medicines.org.uk/emc/ medicine $/ 25506 / \mathrm{SPC} /$ Lantus $+100+$ units $+\mathrm{ml}+$ solution+for+injection+in+a+vial/. Accessed 9 May 2014.

54. Insulin Detemir: Summary of product characteristics (EU) (2014). http://www.medicines.org.uk/emc/ medicine/14584/SPC/Levemir++Cartridge+100+U+ $\mathrm{ml}+-+$ Penfill\%2c++Levemir+Pre-filled + Pen $+100+$ 
$\mathrm{U}+\mathrm{ml}+-+$ FlexPen+and+InnoLet/. Accessed 9 May 2014.

55. Insulin Degludec: Summary of Product Characteristics (EU) (2014). http://www.ema. europa.eu/docs/en_GB/document_library/EPAR Product_Information/human/002498/WC500138940. pdf. Accessed 5 Nov 2014.

56. Lepercq J, Lin J, Hall GC, et al. Meta-analysis of maternal and neonatal outcomes associated with the use of insulin glargine versus NPH insulin during pregnancy. Obstet Gynecol Int. 2012;2012: 649070 (Epub May 16, 2012).

57. Mathiesen ER, Hod M, Ivanisevic M, Detemir in Pregnancy Study Group, et al. Maternal efficacy and safety outcomes in a randomized, controlled trial comparing insulin detemir with NPH insulin in 310 pregnant women with type 1 diabetes. Diabetes Care. 2012;35:2012-7.

58. Hod M, Mathiesen ER, Jovanovič L, et al. A randomized trial comparing perinatal outcomes using insulin detemir or neutral protamine Hagedorn in type 1 diabetes. J Matern Fetal Neonatal Med. 2014;27:7-13.

59. Pollex EK, Feig DS, Lubetsky A, Yip PM, Koren G. Insulin glargine safety in pregnancy: a transplacental transfer study. Diabetes Care. 2010;33:29-33.

60. Sommerfeld MR, Müller G, Tschank G, et al. In vitro metabolic and mitogenic signaling of insulin glargine and its metabolites. PLoS One. 2010;5:e9540.

61. Bolli GB, Hahn AD, Schmidt R, et al. Plasma exposure to insulin glargine and its metabolites M1 and M2 after subcutaneous injection of therapeutic and supratherapeutic doses of glargine in subjects with type 1 diabetes. Diabetes Care. 2012;35:2626-30.

62. Lucidi P, Porcellati F, Rossetti P, et al. Metabolism of insulin glargine after repeated daily subcutaneous injections in subjects with type 2 diabetes. Diabetes Care. 2012;35:2647-9.

63. Bordeleau L, Yakubovich N, Dagenais GR, et al. The association of basal insulin glargine and/or n-3 fatty acids with incident cancers in patients with dysglycemia. Diabetes Care. 2014;37:1360-6.

64. DeFelippis MR, Bakaysa DL, Bell MA, et al. Preparation and characterization of a cocrystalline suspension of [LysB28, ProB29]-human insulin analogue. J Pharm Sci. 1998;87:170-6.

65. Ceriello A, Cremasco F, Romoli E, Rossi A, Gentilella R. Insulin lispro protamine suspension in the treatment of patients with type 1 and type 2 diabetes mellitus: a systematic review of published data. Expert Opin Pharmacother. 2012;13:255-81.

66. Roach P, Woodworth JR. Clinical pharmacokinetics and pharmacodynamics of insulin lispro mixtures. Clin Pharmacokinet. 2002;41:1043-57.

67. Janssen MM, Casteleijn S, Devillé W, Popp-Snijders C, Roach P, Heine RJ. Nighttime insulin kinetics and glycemic control in type 1 diabetes patients following administration of an intermediate-acting lispro preparation. Diabetes Care. 1997;20:1870-3.

68. Hompesch M, Ocheltree SM, Wondmagegnehu ET, et al. Pharmacokinetics and pharmacodynamics of insulin lispro protamine suspension compared with insulin glargine and insulin detemir in type 2 diabetes. Curr Med Res Opin. 2009;25:2679-87.

69. Korsatko S, Glettler K, Olsen KJ, et al. A direct comparison of the pharmacodynamic properties of insulin detemir and neutral protamine lispro insulin in patients with type 1 diabetes. Diabetes Obes Metab. 2013;15:241-5.

70. Ocheltree SM, Hompesch M, Wondmagegnehu ET, Morrow L, Win K, Jacober SJ. Comparison of pharmacodynamic intrasubject variability of insulin lispro protamine suspension and insulin glargine in subjects with type 1 diabetes. Eur J Endocrinol. 2010;163:217-23.

71. Citro G, Lorusso B, Rossi A, Romaniello M, Gentilella R, Cremasco F. Insulin lispro protamine suspension in intensive insulin treatment: an Italian observational study. Curr Med Res Opin. 2009;25:2259-65.

72. Roach P, Strack T, Arora V, Zhao Z. Improved glycaemic control with the use of self-prepared mixtures of insulin lispro and insulin lispro protamine suspension in patients with types 1 and 2 diabetes. Int J Clin Pract. 2001;55:177-82.

73. Chacra AR, Kipnes M, Ilag LL, Sarwat S, Giaconia J, Chan J, COMPLETE T1D investigators. Comparison of insulin lispro protamine suspension and insulin detemir in basal-bolus therapy in patients with type 1 diabetes. Diabet Med. 2010;27:563-9.

74. Arakaki RF, Blevins TC, Wise JK, et al. Comparison of insulin lispro protamine suspension versus insulin glargine once daily added to oral antihyperglycaemic medications and exenatide in type 2 diabetes: a prospective randomized open-label trial. Diabetes Obes Metab. 2014;16: $510-8$.

75. Esposito K, Ciotola M, Maiorino MI, et al. Addition of neutral protamine lispro insulin or insulin glargine to oral type 2 diabetes regimens for 
patients with suboptimal glycemic control: a randomized trial. Ann Intern Med. 2008;149:531-9.

76. Fogelfeld L, Dharmalingam M, Robling K, Jones C, Swanson D, Jacober S. A randomized, treat-to-target trial comparing insulin lispro protamine suspension and insulin detemir in insulin-naive patients with type 2 diabetes. Diabet Med. 2010;27:181-8.

77. Koivisto V, Cleall S, Pontiroli AE, Giugliano D. Comparison of insulin lispro protamine suspension versus insulin glargine once daily in basal-bolus therapies with insulin lispro in type 2 diabetes patients: a prospective randomized open-label trial. Diabetes Obes Metab. 2011;13:1149-57.

78. Strojek K, Shi C, Carey MA, Jacober SJ. Addition of insulin lispro protamine suspension or insulin glargine to oral type 2 diabetes regimens: a randomized trial. Diabetes Obes Metab. 2010;12:916-22.

79. Esposito K, Chiodini P, Capuano A, Petrizzo M, Improta MR, Giugliano D. Basal supplementation of insulin lispro protamine suspension versus insulin glargine and detemir for type 2 diabetes: meta-analysis of randomized controlled trials. Diabetes Care. 2012;35:2698-705.

80. Colatrella A, Visalli N, Abbruzzese S, Leotta S, Bongiovanni M, Napoli A. Comparison of insulin lispro protamine suspension with NPH insulin in pregnant women with type 2 and gestational diabetes mellitus: maternal and perinatal outcomes. Int J Endocrinol. 2013;2013:151975.

81. Dalfra M, Filippi A, Soldato A, et al. Preliminary data on pregnancy outcome of diabetic mothers treated with basal insulin lispro-protamine in a multicentre study in northeast of Italy. Diabetologia. 2013;56(Suppl 1):S505.

82. Dalfrà $\mathrm{MG}$, Soldato $\mathrm{A}$, Moghetti $\mathrm{P}$, et al. Diabetic pregnancy outcomes in mothers treated with basal insulin lispro protamine or NPH insulin: a multicenter retrospective Italian study. J Matern Fetal Neonatal Med. 2015;21:1-5 (Epub ahead of print). 